\title{
Night Awakening and Its Association With Executive Functioning Across the First Two Years of Life
}

\author{
Tiina E. Mäkelä (D) and Mikko J. Peltola (iD \\ Tampere University
}

\author{
Tiina Paunio and E. Juulia Paavonen \\ National Institute for Health and Welfare and University of \\ Helsinki and Helsinki University Hospital
}

\author{
Outi Saarenpää-Heikkilä and Sari-Leena \\ Himanen \\ Tampere University and Tampere University Hospital
}

\begin{abstract}
Longitudinal associations between signaled night awakening and executive functioning (EF) at 8 and 24 months in children with $(\geq 3$ awakenings, $n=77)$ and without parent-rated fragmented sleep $(\leq 1$ awakening, $n=69$ ) were studied. EF was assessed with the Switch task at 8 and 24 months. At 24 months, behavioral tasks and parental ratings of EF (Behavior Rating Inventory of Executive Function-Preschool version) were also used. In the Switch task, children with fragmented sleep were less able to learn stimulus sequences and inhibit previously learned responses than children without fragmented sleep. The groups differed only marginally in parental ratings of EF, and no differences were found in behavioral EF tasks. These results suggest that eye movement-based measures may reveal associations between sleep and EF already in infancy and toddlerhood.
\end{abstract}

Sleep can be considered one of the most important functions during early development. By the age of 2 years, an infant has spent over half of his or her life in a sleeping state (Dahl, 1996a). In infancy, a typical feature of sleep is its fragmentation (i.e., night awakenings that are followed by periods of wakefulness after sleep onset). Night awakenings are normative between sleep stages (Anders, 1978), but persistent signaled night awakenings are a burden for the entire family (Sadeh, Flint-Ofir, Tirosh,

We thank all the families who have participated in the CHILD-SLEEP birth cohort. We are also grateful to the nurses at the maternity clinics who introduced the study to the families. We also thank Isabel Morales for analyzing the actigraphy data. The project was funded by the Academy of Finland (\#308588 E. Juulia Paavonen; \#134880 and \#253346 Tiina Paunio; \#326631 Anneli Kylliäinen; \#307657 Mikko J. Peltola; \#277557 Outi Saarenpää-Heikkilä), the Gyllenberg Foundation (Tiina Paunio), the Yrjö Jahnsson Foundation, the Foundation for Pediatric Research, the Finnish Cultural Foundation, the Competitive Research Financing of the Expert Responsibility Area of Tampere University Hospital (Grants 9P013, 9R007, 9S007, 9T008), the Arvo and Lea Ylppö Foundation, and the Doctors' Association in Tampere. All authors contributed to the planning of the study design and data collection. TEM, MJP, and AK were primarily responsible for the data analysis and the writing of the article. EJP, OS-H, S-LH, and TP contributed critically to the writing of the article.

Correspondence concerning this article should be addressed to Tiina E. Mäkelä, Psychology, Faculty of Social Sciences, Tampere University, 33014 Tampere, Finland. Electronic mail may be sent to tiina.makela@tuni.fi.
\& Tikotzky, 2007). Signaled night awakening refers to night awakenings that are signaled to their parent, for example, with crying. Approximately $20 \%-$ $30 \%$ of 1-year-old infants (Adair, Zuckerman, Bauchner, Philipp, \& Levenson, 1992; Mindell, Kuhn, Lewin, Meltzer, \& Sadeh, 2006) and still $15 \%-50 \%$ of 2 - to 5 -year-old children continue to have night awakenings (Hysing, Sivertsen, GarthusNiegel, \& Eberhard-Gran, 2016; Petit, Touchette, Tremblay, Boivin, \& Montplaisir, 2007). Several child- and parent-related factors have been associated with increased night awakening. These factors include the child's temperament and parental practices when putting the child to sleep, co-sleeping with the infant, and whether the child is breastfed or not (Hysing et al., 2014; Sadeh, Mindell, Luedtke, \& Wiegand, 2009; Touchette et al., 2005). According to previous studies, however, the direction of causality between these factors and night awakening is still not clear. Researchers have attempted to determine whether fragmented sleep is also a risk factor for the child's psychological development, and whether some aspects of development are more

(C) 2019 Society for Research in Child Development All rights reserved. 0009-3920/2019/xxxx-xxxx DOI: $10.1111 /$ cdev. 13326 


\section{Mäkelä et al.}

vulnerable to the effects of fragmented sleep than others (Sadeh, Gruber, \& Raviv, 2002). In infancy, however, the connections between sleep and development have not been sufficiently studied. Recent research has suggested that one area that might be especially vulnerable to the effects of sleep fragmentation is executive functioning (EF), due to its long course of maturation and strong associations with the development of the frontal lobes (Bernier, Beauchamp, Bouvette-Turcot, Carlson, \& Carrier, 2013).

The development of EF begins during infancy and continues into early adulthood. EF refers to higher-order cognitive processes, and it consists of interrelated functions such as impulse control, set shifting, and working memory (Lehto, Juujärvi, Kooistra, \& Pulkkinen, 2003; Miyake et al., 2000). EF is considered part of the broader concept of selfregulation, which refers to the flexible control of cognition, emotion, and behavior (Bridgett, Burt, Edwards, \& Deater-Deckard, 2015; Nigg, 2017). The first 6 years of human life play a critical role in the development of EF (Garon, Bryson, \& Smith, 2008; Zelazo, Carter, Reznick, \& Frye, 1997). During early development, parents externally regulate their infant's behavior by directing their attention and helping infants in inhibiting their own behavior. After the first year, more emphasis is given to the child's internal regulation, with working memory and inhibition developing first. Set shifting requires and builds upon working memory and inhibition, and it therefore develops later than the other EF components (Garon et al., 2008). Previous studies have shown modest stability in EF during infancy, with the size of the association depending on the EF component being measured (Bernier, Carlson, Bordeleau, \& Carrier, 2010; Wolfe, Zhang, KimSpoon, \& Bell, 2014). The stability of EF has been found to increase during childhood (Best \& Miller, 2010). In general, EF skills have been found to predict, for example, later school success (Borella, Carretti, \& Pelegrina, 2010; Duncan et al., 2007) and quality of life (Brown \& Landgraf, 2010; Davis, Marra, Najafzadeh, \& Liu-Ambrose, 2010).

Previous studies with school-aged children and adolescents have shown that sleep difficulties impair performance in EF-related tasks (Astill, Van der Heijden, Van IJzendoorn, \& Van Someren, 2012). For example, studies with school-aged children have supported the notion that shorter nocturnal sleep duration (Astill et al., 2012; Steenari et al., 2003) and sleep fragmentation (Sadeh et al., 2002) are negatively connected to EF. Sadeh, Gruber, and Raviv (2003) also showed that $30 \mathrm{~min}$ of extended sleep enhanced children's performance in a task measuring sustained attention and inhibition, but no enhancement was seen in tasks that required low cognitive load. In preschool-aged children, shorter nocturnal sleep duration has been associated with poorer attentional control (Lam, Mahone, Mason, \& Scharf, 2011) and mother-reported EF skills (Taveras, Rifas-Shiman, Bub, Gillman, \& Oken, 2017). Thus, based on these studies with preschool- and school-aged children, sleep duration and sleep fragmentation appears to influence EF. It is not clear, however, if the connections between fragmented sleep and EF can be observed already in infancy.

In infancy, the significance of sleep might be even greater than later in development due to major ongoing developmental processes in both sleep and neuro-behavioral functioning (Dahl, 1996b). However, only a few longitudinal studies have investigated the associations between sleep quality and EF in infancy. Bernier et al. (2010) showed that the amount of night-centered sleep at 12 and 18 months of age was positively related to performance in a behavioral EF task that required impulse control when the infants were 26 months old. In addition, infants whose sleep was more focused to the nighttime at 18 months of age showed increased performance in a concurrent working memory task. In their follow-up study, the amount of nighttime sleep at 12 months of age was positively related to EF even at the age of 4 years (Bernier et al., 2013). Thus, it appears that over time, more matured sleep benefits performance in EF tasks.

The relation between EF and night awakening in infancy, however, is not clear. Night awakening is a common concern for parents, and persistent night awakening also disrupts parents' sleep and can result in prolonged sleep deprivation (Karraker, 2008). Previous studies have shown that parental sleep patterns are highly connected to their children's sleep patterns (Boergers, Hart, Owens, Streisand, \& Spirito, 2007; Gay, Lee, \& Lee, 2004; Meltzer \& Mindell, 2007). Sadeh et al. (2015) found that a greater amount of night awakenings in 1-year-olds predicted poorer performance in a computerized method of attention regulation at 34 years of age, whereas Bernier et al. (2010) did not find a relation between night awakenings at 1 year of age and behavioral EF measures at 2 years of age. These behavioral measures consisted of tasks measuring working memory, inhibitory control, and set shifting. The results of these two studies are not entirely comparable since they used very 
different methods for measuring EF and the domain of EF being studied varied. EF was also measured at two different developmental periods, which may further explain the conflicting results. In addition, Sadeh et al. (2015) measured night awakenings with actigraphy whereas Bernier et al. (2010) measured night awakenings with sleep diaries that were filled by mothers. Additionally, night awakening and its influence on $\mathrm{EF}$ has not been studied in infants under 1 year of age.

In recent years, new methods have emerged that enable the study of EF in infants under 1 year of age (Best \& Miller, 2010; Kovács \& Mehler, 2009), but they have not been utilized in the field of sleep research. In this study, we used the Switch task, developed by Kovács and Mehler (2009), which is an eye movement-based measure of infant EF. In the Switch task, infants are first required to learn a predictable stimulus sequence and, in the second phase, to inhibit their previously learned response in order to learn a new conflicting response. Hence, the Switch task may require each EF domain, although in infancy and toddlerhood, EF may manifest as a more unitary construct and the different domains of EF may not be easily distinguishable (Espy, Sheffield, Wiebe, Clark, \& Moehr, 2011; Shing, Lindenberger, Diamond, Li, \& Davidson, 2010; Wiebe, Espy, \& Charak, 2008). However, the Switch task has been used in previous studies as an early indicator of these abilities (Kovács \& Mehler, 2009; Wass, Porayska-Pomsta, \& Johnson, 2011). In a study of bilingual infants, Kovács and Mehler (2009) showed that bilingual infants are better able to inhibit their responses and learn a new conflicting response than monolingual infants. In addition, Forssman et al. (2017) have shown the Switch task to be a feasible method in various cultures and in socioeconomically challenging settings in infants under 1 year of age. The Switch task has also been used as an indicator of EF in a study of attentional control training in infants (Wass et al., 2011). One advantage of the Switch task in this study is that it can be used longitudinally, as the same task could be presented to both 8- and 24-month-old children. In addition, at 24 months of age we also used three different behavioral measures that are suitable for 2-year-olds, and a parental evaluation of toddler EF. These behavioral tasks are administered to the child in a playful manner (Carlson, 2005) and were chosen so that all aspects of EF could be measured, including working memory (Spin the Pots; Hughes \& Ensor, 2005), set shifting (Trucks task; Hughes \& Ensor, 2005), and inhibitory control (Snack Delay; Kochanska, Murray, \& Harlan, 2000).
In this study, we studied signaled infant night awakening and its concurrent and longitudinal associations with children's EF. Our study concentrates on sleep in infancy and toddlerhood and its connection with EF, a topic that has received little attention in previous studies. In addition, our goal was to combine novel eye-movement-based methods with an adequate sample size in the study of infant EF. For that purpose, two groups of infants with and without signaled night awakenings were formed at the age of 8 months within the CHILDSLEEP birth cohort (Mäkelä et al., 2018; Paavonen et al., 2017). In an additional analysis, actigraphy data were used to assess the validity of the group formation based on parent-reported night awakening. In this study, we measured EF with the Switch task (Kovács \& Mehler, 2009) at 8 and 24 months of age. Our goal was to measure EF with various methods and, therefore, at 24 months of age, we also included age-appropriate behavioral tasks for the measurement of EF together with a parent-rated measure of EF. Our aim was to investigate whether signaled night awakening at 8 months of age is connected to infant EF, and whether the possible differences in EF could be observable already during the first year of life. For the hypotheses regarding the 8-month data, we adopted an exploratory approach and had no definitive hypothesis on the associations between signaled night awakening and infant EF, since in prior studies, signaled night awakening and $\mathrm{EF}$ have not been studied in infants under 1 year of age. At 24 months of age, however, we expected that the children with several signaled night awakenings at 8 months of age would show lower performance in various EF tasks and parentrated EF, as suggested by studies conducted with older children (Sadeh et al., 2015; Sadeh et al., 2002).

\section{Method \\ Participants}

The participants of this study were recruited from within the CHILD-SLEEP longitudinal birth cohort, $n=1,667$ (Mäkelä et al., 2018; Paavonen et al., 2017). The participants for the cohort were recruited through maternity clinics approximately on 32nd gestational week by their maternity nurse. Participating families received questionnaires before birth and when their child was 3, 8, 18 , and 24 months of age. There were separate questionnaires for mothers, fathers, and the child. In order to form two groups of infants based on 


\section{Mäkelä et al.}

the number of signaled night awakenings, the parents of 8-month-old infants from one substudy of the cohort $(n=406)$ were approached through a phone call and asked how many times their infant woke during the night. Infants with three or more signaled night awakenings during the night (between midnight and $6 \mathrm{a}$.m.) were asked to participate in the study; they formed the waking group. Infants with no more than one signaled night awakening during the night formed the nonwaking group. Infants with two signaled night awakenings were not included in this study, as our aim was to compare two clearly distinguishable groups in the analyses. The Ethics Committee of Pirkanmaa Hospital District reviewed the study protocol (R11032) and the parents completed a consent form before participation. The children received a small toy for their participation at both assessment points. In total, 146 white Finnish infants participated at 8 months of age, with 77 infants in the waking group $\left(M_{\text {age }}=0.5\right.$ months, $S D=0.4$ months) and 69 infants in the nonwaking group $\left(M_{\text {age }}=8.6\right.$ months, $S D=0.4$ months $)$. At 24 months of age, 65 infants from the waking group $\left(M_{\text {age }}=24.6\right.$ months, $S D=2.2$ months $)$ and 56 infants from the nonwaking group $\left(M_{\text {age }}=24.5\right.$ months, $S D=2.9$ months $)$ returned for another assessment $(n=121,83 \%$ retention rate). There were no differences between the participants who remained or dropped out of the study after the 8-month assessment in the Switch task performance or parent-reported sleep parameters (nocturnal, daytime, and total sleep duration, time spent awake during the night, and sleep latency), all $p s>$.192. Two additional participants were examined but excluded from further analysis due to prematurity $(n=1)$ and the parents' native language being other than Finnish $(n=1)$. The demographic statistics of the sample are shown in Table 1. At 8 months of age, we had actigraphy data from $88 \%$ of the participants in the waking group $(n=68)$ and $89 \%$ of participants in the nonwaking group $(n=61)$. At 24 months of age, the retention rate was lower so that only $55 \%$ of the waking group $(n=36)$ and $50 \%$ of the nonwaking group $(n=28)$ returned the actigraphy assessment. Therefore, the actigraphy data are reported only for the 8-month assessment point. The waking group and the nonwaking group did not differ in overall psychomotor development (measured with the Bayley-III) or in other child- or mother-related features (child's gender and age, number of children in the family, or maternal education; for details, see Mäkelä et al., 2018). At 8 months of age, however, the two groups differed in the amount of cosleeping $\left(\chi^{2}(1, n=119)=20.376\right.$, $p<.001)$, breastfeeding $\left(\chi^{2}(1, n=133)=13.413\right.$, $p=.001)$, and the infant's ability to fall asleep alone $\left(\chi^{2}(1, n=133)=16.454, p<.001\right.$; Table 1$)$. The infants in the waking group were more likely to co-sleep with their parents, be breastfed and not be able to fall asleep alone than the infants in the nonwaking group. For the analysis, these variables were categorized. Cosleeping was categorized as less than twice in a month or at least weekly cosleeping with the parent. The ability to fall asleep alone was categorized as the infant being able to fall asleep alone only once in a week or at least once a day. Breastfeeding was categorized as the infant being only breastfed, both breastfed and formula fed, or only formula fed. Therefore, these three factors were included in the analysis as covariates, even though in our previous work, these covariates were not connected to psychomotor development (Mäkelä et al., 2018). The infants in this study were recruited from a prevention substudy of the main cohort in which healthcare centers in Tampere, Finland, were randomized into prevention and control healthcare centers. Families in the prevention group received preventive psychoeducation on how to support infant sleep quality through brochures, whereas the control group received standard well-child visit information. The infants in this study came from both the prevention and control healthcare centers $\left(\chi^{2}(1, n=146)=3.394\right.$, $p=.065$; Table 1). The healthcare center status was included as a covariate in the analyses to determine whether it affected the findings. Finally, our previous work showed that the infants with fragmented sleep had a shorter total sleep duration and spent more time awake during the night (Mäkelä et al., 2018). These sleep characteristics were also included as covariates in our analysis. A comprehensive description of the different sleep parameters in the waking and nonwaking groups is provided in Table 2.

\section{Procedure}

The study protocol consisted of two separate research visits at both 8 and 24 months of age. During the first visit, psychomotor development was measured (reported in reported in Mäkelä et al., 2018). During the second research visit, the EFrelated tasks were conducted in the research laboratory. At 8 months of age, the research visit consisted of computer tasks measuring EF (i.e., the 
Table 1

Descriptive Statistics for the Two Groups

\begin{tabular}{|c|c|c|c|c|c|}
\hline & \multicolumn{2}{|c|}{$\begin{array}{c}\text { Waking } \\
\text { group }\end{array}$} & \multicolumn{2}{|c|}{$\begin{array}{l}\text { Nonwak- } \\
\text { ing } \\
\text { group }\end{array}$} & \multirow[b]{2}{*}{$p$} \\
\hline & $n$ & $\%$ & $n$ & $\%$ & \\
\hline Gender & & & & & .889 \\
\hline Girls & 33 & 43.4 & 34 & 49.3 & \\
\hline Boys & 43 & 56.6 & 35 & 50.7 & \\
\hline Siblings & & & & & .354 \\
\hline Yes & 27 & 36.5 & 33 & 34.2 & \\
\hline No & 47 & 63.5 & 34 & 50.7 & \\
\hline Mother's education & & & & & .210 \\
\hline$>15$ years & 36 & 47.4 & 31 & 45.2 & \\
\hline$<15$ years & 40 & 52.6 & 37 & 54.8 & \\
\hline Father's education & & & & & .671 \\
\hline$>15$ years & 55 & 70.5 & 45 & 70.3 & \\
\hline$<15$ years & 23 & 29.5 & 16 & 25.0 & \\
\hline Mother's monthly net income & & & & & .377 \\
\hline$>2,000 €$ & 23 & 29.5 & 23 & 35.9 & \\
\hline $1,000-2,000 €$ & 39 & 50.0 & 24 & 37.5 & \\
\hline$<1,000 €$ & 14 & 17.9 & 14 & 21.9 & \\
\hline Father's monthly net income & & & & & .492 \\
\hline$>2,000 €$ & 49 & 62.8 & 42 & 65.6 & \\
\hline $1,000-2,000 €$ & 20 & 25.6 & 16 & 25.0 & \\
\hline$<1,000 €$ & 8 & 10.3 & 3 & 4.7 & \\
\hline Healthcare center & & & & & .065 \\
\hline Prevention & 43 & 55.8 & 28 & 40.6 & \\
\hline Control & 34 & 44.2 & 41 & 59.4 & \\
\hline Co-sleeping & & & & & $<.001$ \\
\hline$>$ Once in a week & 29 & 44.6 & 4 & 7.4 & \\
\hline$<2$ times a month & 36 & 55.4 & 50 & 92.6 & \\
\hline Breastfeeding & & & & & .002 \\
\hline Breastfed only & 43 & 58.9 & 20 & 33.3 & \\
\hline Breastfed and formula fed & 16 & 21.9 & 11 & 55.0 & \\
\hline Formula fed only & 14 & 19.2 & 29 & 48.3 & \\
\hline Falling asleep alone & & & & & $<.001$ \\
\hline Once in a week & 49 & 68.1 & 20 & 32.8 & \\
\hline Once in a day & 23 & 31.9 & 41 & 67.2 & \\
\hline
\end{tabular}

Switch task) and attention to emotional faces (reported elsewhere), and a separate assessment of child-parent interaction (reported elsewhere). At the age of 24 months, the same tasks were conducted. In addition, at 24 months, three different age-appropriate behavioral EF tasks (Spin the Pots, Trucks, and Snack Delay) were conducted with the child, and the parents filled a questionnaire concerning the child's EF in everyday life (the Behavior Rating Inventory of Executive Function-Preschool version, BRIEF-P; Gioia, Espy, \& Isquith, 2003). The questionnaire was given to the parents during the first research visit and they were asked to return it during the second research visit. A fixed order of tasks was kept throughout the data collection. The EF tasks were conducted in a separate room after the computer tasks. The Spin the Pots task was conducted first, followed by the Trucks task and the Snack Delay task. After the data collection had been completed, it transpired that there were inconsistencies in the presentation of the material in the Trucks task between experimenters. Consequently, the Trucks task was excluded from the data analyses. Finally, in the information letter send to the participants before the first research visit at both ages, the participant received an actigraph device to be worn at home for three consecutive days together with a comprehensive sleep-log, and were asked to return them via mail.

\section{Measures}

\section{8-Month EF Assessment}

The Switch task assesses the ability of children to learn new stimulus sequences and to inhibit their response to a previously learned cue in order to learn a new conflicting response. During the Switch task, the infant sat on his or her parent's lap at an approximately $60-\mathrm{cm}$ distance from a 19-in. computer screen, which was surrounded by a black frame. A video camera was hidden on top of the computer screen in order for the experimenter to observe the child and control stimulus presentation. In addition, video recordings of the Switch task were saved for offline analyses of eye movements. The task was presented with E-prime software (Psychology Software Tools, Pittsburgh, PA). Before starting the task, the lights were dimmed. Parents were instructed not to interact with their child unless it was necessary to soothe the child during the stimulus presentation. In addition, the parents were told that the researcher controlled the stimulus presentation and would start each trial only after the child's eyes were focused on the screen.

Each trial started with a red circle appearing on a gray background. The red circle expanded from $0.4^{\circ}$ to $4.3^{\circ}$ in a continuous fashion in order for the child to focus his or her eyes on the screen. When the child's eyes were focused on the screen, the experimenter initiated each trial. If the child did not focus on the screen, the experimenter called the child by name and initiated the trial only after the child focused on the screen. After that, each trial started with the background turning white, and a brief $(350 \mathrm{~ms})$ auditory beep stimulus was presented from a speaker positioned behind the 


\begin{tabular}{|c|c|c|c|c|c|c|}
\hline & \multicolumn{3}{|c|}{ Waking group } & \multicolumn{3}{|c|}{ Nonwaking group } \\
\hline & $n$ & $M$ & $S D$ & $n$ & $M$ & $S D$ \\
\hline \multicolumn{7}{|l|}{8 months } \\
\hline \multicolumn{7}{|l|}{ Parent-reported } \\
\hline Duration of nocturnal sleep (min) & 75 & 589.9 & 58.4 & 60 & 597.8 & 55.7 \\
\hline Duration of daytime sleep (min) & 76 & 188.4 & 53.6 & 60 & 204.8 & 63.1 \\
\hline Duration of total sleep (min) & 75 & 778.8 & 70.9 & 60 & 802.6 & 60.5 \\
\hline Sleep latency $(\mathrm{min})$ & 74 & 24.8 & 16.9 & 57 & 18.2 & 15.5 \\
\hline Time spent awake at night (min) & 69 & 30.6 & 25.7 & 48 & 15.8 & 20.6 \\
\hline Night awakenings (count) & 73 & 3.8 & 1.9 & 54 & 0.9 & 0.6 \\
\hline Proportion of nighttime sleep (\%) & 75 & 75.9 & 5.8 & 60 & 74.7 & 6.6 \\
\hline \multicolumn{7}{|l|}{ Actigraphy-based } \\
\hline Actual sleep time (min) & 67 & 511.1 & 55.0 & 61 & 518.5 & 56.6 \\
\hline Sleep latency (min) & 66 & 19.3 & 19.3 & 58 & 17.8 & 22.1 \\
\hline Sleep efficiency $(\%)$ & 66 & 78.7 & 6.2 & 58 & 79.1 & 6.8 \\
\hline Proportion of nighttime sleep (\%) & 37 & 85.7 & 5.7 & 31 & 85.1 & 6.6 \\
\hline Activity score in active periods (count) & 68 & 127.0 & 48.7 & 60 & 102.6 & 46.6 \\
\hline \multicolumn{7}{|l|}{24 months } \\
\hline \multicolumn{7}{|l|}{ Parent-reported } \\
\hline Duration of nocturnal sleep (min) & 53 & 589.4 & 46.4 & 41 & 605.5 & 37.9 \\
\hline Duration of daytime sleep (min) & 53 & 105.4 & 38.8 & 41 & 114.6 & 46.1 \\
\hline Duration of total sleep (min) & 53 & 694.8 & 45.3 & 41 & 720.6 & 55.5 \\
\hline Sleep latency $(\mathrm{min})$ & 48 & 23.9 & 18.1 & 38 & 17.9 & 12.5 \\
\hline Time spent awake at night (min) & 46 & 11.8 & 12.3 & 38 & 4.0 & 9.0 \\
\hline Night awakenings (count) & 50 & 1.0 & 0.9 & 40 & 0.6 & 0.6 \\
\hline Proportion of nighttime sleep (\%) & 53 & 84.9 & 5.1 & 41 & 84.3 & 5.1 \\
\hline \multicolumn{7}{|l|}{ Actigraphy-based } \\
\hline Actual sleep time (min) & 35 & 539.7 & 43.0 & 28 & 542.8 & 46.6 \\
\hline Sleep latency (min) & 36 & 26.6 & 18.7 & 28 & 22.3 & 15.0 \\
\hline Sleep efficiency (\%) & 36 & 81.7 & 5.6 & 28 & 83.8 & 4.2 \\
\hline Proportion of nighttime sleep (\%) & 31 & 87.4 & 7.4 & 17 & 89.4 & 5.9 \\
\hline Activity score in active periods (count) & 36 & 82.8 & 31.8 & 28 & 76.4 & 31.0 \\
\hline
\end{tabular}

midpoint of the screen. Simultaneously with the sound, two rectangles $\left(11.6^{\circ} \times 11.2^{\circ}\right)$ with black borders appeared on the left and right side of the screen $\left(11.5^{\circ}\right.$ from the midpoint of the screen). After 1,855-1,900 ms (with an approximately $50 \mathrm{~ms}$ jitter in the stimulus timing caused by an inadvertent error), an animated target stimulus of a monkey doing somersaults $\left(4.6^{\circ} \times 3.8^{\circ}\right)$ appeared in one of the rectangles together with a bell sound for $4,000 \mathrm{~ms}$. For the first nine trials, the target stimulus always appeared on the same side of the screen (preswitch block), after which the target appeared on the other side of the screen for the remaining nine trials (postswitch block). The order of the target location from pre to postswitch blocks (left-right, rightleft) was balanced across participants. An example of a trial in the Switch task is shown in Figure 1. Altogether, the duration of the Switch task was $2.5 \mathrm{~min}$.

\section{4-Month EF Assessment}

At 24 months of age, there were only few modifications to the Switch task. First, the stimuli were presented on a 21-in. screen compared to the 19-in. screen used at 8 months of age. Second, the toddler's eye movements were recorded with a Tobii TX300 eye-tracker (Tobii Technology AB, Stockholm, Sweden). Eye-tracker calibration and stimulus presentation were controlled with Tobii Studio software. Before starting the experiment, the eyetracker cameras were calibrated with a five-point calibration procedure in which a cat appeared with a beep sound in every corner and in the center of the screen. Third, the Switch task was shortened from 18 to 12 trials in total (six trials to both sides).

In the Spin the Pots task, considered to measure working memory (Hughes \& Ensor, 2005), six different treats (raisins or cereals) were hidden under 
Fixation Stimulus

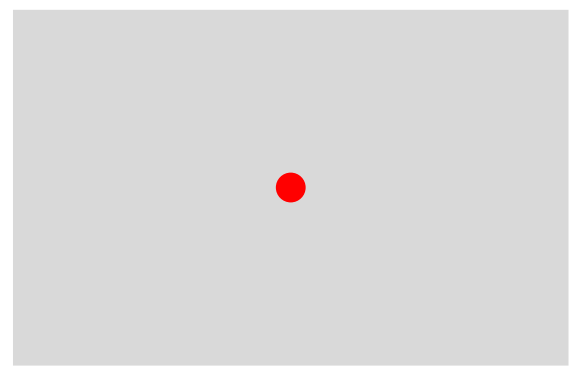

Two Rectangles with Black Borders

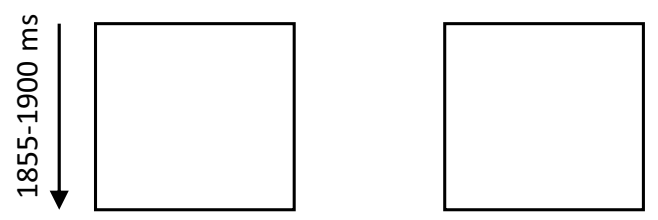

Target Stimulus
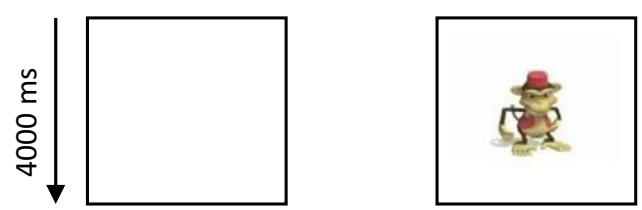

Figure 1. An example of a trial in the Switch task.

eight visually different looking opaque pots. The hiding of the treats was done in front of the toddler and two of the empty pots were also shown to the toddler. After that, the tray containing the pots was covered with a scarf and rotated $180^{\circ}$. Then, the toddler was asked to find the treats by looking under the pots. The toddler was allowed to eat the treats that were discovered under the pots. After each attempt, the tray was again covered and rotated $180^{\circ}$. The task was coded offline from video recordings. The maximum number of trials was 12. The score was calculated as the number of maximum trials minus the errors the toddler made. These errors consisted of perseverative looking or looking under the pots with no treats. The task scores varied between 0 and 12, with higher scores indicating better performance. The duration of the task varied between 2 to 8 min depending on the number of trials the toddler needed to perform the task.

In the Snack Delay task (Kochanska et al., 2000), which was developed to measure inhibitory control, a small candy was placed on top of a tiny candy box in front of the toddler. The toddler was told that she or he had to wait until the bell rang, and only afterward could he or she have the candy. Three different trials were performed with an increasing waiting time of 10,20 , or $30 \mathrm{~s}$. The toddlers were reminded of the rule before every trial. On the $30 \mathrm{~s}$ trial, the experimenter placed her hand on the bell when $20 \mathrm{~s}$ had elapsed, but rang the bell only after $30 \mathrm{~s}$. The toddlers' behavior was coded from video recordings and the score was calculated as the number of seconds the toddlers waited before touching the candy box. The task scores varied between 0 and 60, with higher scores indicating better performance. The duration of the task was approximately $2 \mathrm{~min}$.

BRIEF- $P$ is a parent-rated questionnaire that assesses EF in children from 2 years to 5 years and 11 months of age (Gioia et al., 2003; Isquith, Crawford, Espy, \& Gioia, 2005). It consists of 63 items, and parents answer on a 3-point scale (never/sometimes/often), with higher scores representing a lower EF ability. BRIEF-P yields five different scales labeled "Inhibit," "Shift," "Emotional control," "Working memory," and "Plan/Organize," from which three different indexes are combined. These indexes are ISCI (Inhibition Self-control Index), FI (Flexibility Index), and EMC (Emergent Metacognition Index). The ISCI index comprises the inhibit and emotional control scales, FI comprises the shift and working memory scales, and EMC comprises the working memory and plan/organize scales. In addition, a Global Executive Composite index (GEC) can be formed by combining the scores of all five scales. In this study, a Finnish translation of the test was used. The raw scores of each scale were converted to age- and gender-specific standardized $t$-scores $(M=50, S D=10)$ according to the original norms. Different BRIEF-P scales and indexes showed good internal consistency (Inhibit, $\alpha=.838$; Shift, $\alpha=.780$; Emotional control, $\alpha=.811$; Working memory, $\alpha=.878$; Plan/Organize, $\alpha=.782$; ISCI, $\alpha=.873$; FI, $\alpha=.881$; EMI, $\alpha=.910$; GEC, $\alpha=$ .943). These values are highly similar to the original alphas reported by Gioia et al. (2003).

Actigraphy-based sleep measures were gathered with Actiwatch AW7 activity monitors (Cambridge Neurotechnology Ltd, Cambridge, UK). Parents of 8-month-old infants were instructed to place the actigraphy on their infant's ankle for three consecutive days and to keep a detailed sleep-log. Actigraphs and sleep-logs were initiated at midnight and therefore the number of continuous nights varied between two to four nights depending on how many nights the parents had filled to the sleep-log. 
From the sleep-log variables, parent-reported time to fall asleep and morning wake up time were used in the analysis.

\section{Data analysis}

\section{Video Coding at 8 Months}

The eye movements in the Switch task were analyzed using VirtualDubMod software 1.5.10.2 (http://virtualdubmod.sourceforge.net/). A trained observer, blind to the child's group status, coded all the videos offline. Eye movements were examined manually, frame by frame, with one frame lasting $40 \mathrm{~ms}$. If the child did not focus his or her attention to the screen at the beginning of the trial, the trial was rejected. Anticipatory eye movements toward the target location (the correct rectangle where the monkey would appear) within a time window of $160 \mathrm{~ms}$ after trial onset until $160 \mathrm{~ms}$ after the target onset were coded. Eye movements were considered anticipatory if the first saccade was to the correct target location. Trials were rejected if eye movements were undetectable due to movement. The proportion of correct anticipatory eye movements toward the target location were calculated separately for the preswitch block (first nine trials) and the postswitch block (last nine trials) for all scorable/successful trials. Infants with more than three bad trials within the pre or postswitch block were excluded from the analyses. For the infants included in the analyses, the average numbers of scorable trials in the pre and postswitch blocks were 8.6 and 8.5 , respectively, with no difference between the blocks $(t(242)=1.310, p=.192)$. To ensure coding reliability, two independent observers coded $25 \%$ of all cases $(n=37)$. Intercoder agreement (intraclass correlation) on the proportion of anticipatory looks in both the pre and postswitch blocks between the main coder and the reliability coders was .97 .

\section{Eye-Tracking Analysis at 24 Months}

The eye-tracking data of the Switch task were saved as text files and analyzed with gazeAnalysisLib, a library of Matlab routines for gaze data analysis (Leppänen, Forssman, Kaatiala, Yrttiaho, \& Wass, 2015). The areas of interest were manually defined, and these areas covered the central area of the screen, the rectangle where the monkey appeared, and the area between the center and the rectangle. Eye movements were coded as anticipatory if the toddler made the first saccade toward the box where the monkey would appear. The proportion of correct anticipatory eye movements was calculated similarly as in the 8-month analyses, that is, separately for the preswitch block (first six trials) and the postswitch block (last six trials) conditions. The average numbers of scorable trials in the pre and postswitch blocks were 4.3 and 3.9 , respectively, with no difference between the blocks $(t(236)=1.477, p=.141)$. The correlations between video-based (i.e., manually coded) and eye-tracking data from children saccadic response tasks have been shown to be very high (Leppänen et al., 2015).

\section{Actigraphy Analysis at 8 Months}

Activity counts were summed over 1-min-intervals (for detailed description of the algorithm, see Oakley, 1997, and Kushida et al., 2001). Actigraphybased sleep measures are not directly comparable to parent-reported sleep measures, especially when considering parent-reported signaled night awakening. To this end, we considered the actigraphybased nocturnal activity measure (mean score during active periods at night) to most closely reflect the same phenomenon as signaled night awakening. Mean score during active periods is the total activity score divided by the number of epochs with greater than zero activity. In addition to this activity parameter, the actigraphy data were also analyzed with a smoothing algorithm in order to decrease the number of actigraphy-based night awakenings, many of which may represent movements that are unrelated to signaled night awakenings (Sitnick, Goodlin-Jones, \& Anders, 2008). When the smoothing algorithm is applied, the start of the awakening requires two or more consecutive minutes with activity counts $>100$. If these epochs are preceded by an epoch with activity count greater than zero, that epoch was considered to indicate the start of the awakening. The awakening was considered to end at the first of three consecutive minutes with no activity. The mean value of these awakenings was as calculated for two consecutive nights ensuring constant amount of data between participants.

\section{Statistical Analysis}

Statistical analyses were conducted with SPSS 25 (IBM Corp., Armonk, NY). The distributions of continuous outcome variables were screened with box-plots and scatterplots, and no extreme outliers 
were observed. To analyze the group differences in the Switch task longitudinally, a Linear Mixed Model (LMM) was used since the LMM allowed us to utilize the longitudinal incomplete data. In the analysis, within-factors, between-factors, and their interactions were analyzed. Age (8 and 24 months) and Block (preswitch block and postswitch block) were used as within-factors. The between-factor was Group status (waking group and nonwaking group). In addition, their interactions were included in the model. In the case of statistically significant main effects, the differences between subgroups were further analyzed using Bonferroni-corrected post hoc tests. Effect sizes for the pairwise comparisons are indicated by Cohen's $d$. First, we ran a model that included all the within- and betweenfactors and their interactions, as well as the covariates that differentiated between the two groups (cosleeping, breastfeeding, ability to fall asleep alone, healthcare center status, sleep duration, and time spent awake during the night). None of the covariates (all $p$-values $>.184$ ) or interactions were significant (all $p$-values $>.113$ ) and, therefore, the final models consisted of the within- and betweenfactor main effects. Group differences in the BRIEF$\mathrm{P}$ questionnaire, Spin the Pot, Snack Delay, and actigraphy-based activity measures were analyzed with $t$-tests. The alpha level was set at $p<.05$.

\section{Results}

In the Switch task, the LMM revealed main effects of Block $(F(1,190.949)=63.312, p<.001, d=1.54)$ and Group $(F(1,226.791)=4.492, p=.035, d=0.36)$. Children had more correct anticipations in the preswitch block $(M=0.734, S E=.019)$ than in the postswitch block $(M=0.478, S E=.021)$. In addition, the nonwaking group $(M=0.631, S E=.018)$ had overall a higher percentage of correct anticipations than the waking group $(M=0.580, S E=.017)$. However, the interactions were nonsignificant [Group $\times$ Block $(F$ $(1,129.258)=0.110, p=.741$, Group $\times$ Age $(F(1$, $136.684)=2.539, p=.113)$, and Group $\times$ Age $\times$ Block $(F(2,129.692)=1.572, p=.212)]$, indicating that the differences between groups were not specific only to the preswitch or postswitch block, or to either age. Since these interactions were nonsignificant, they were excluded from the final model.

For our research question concerning how early the potential differences in EF between infants with and without fragmented sleep would be observable, we nevertheless considered it important to further explore whether the differences between groups were already visible at 8 months of age, or whether the differences between groups were more pronounced at 24 months of age as indicated by visual inspection of Figure 2. Therefore, we decided to conduct the analyses separately for the 8- and 24month data. Both analyses consisted of the withinfactor Block and between-factor Group, and their interaction. For the final model reported here, only statistically significant factors and the between-factor Group were included. The LMM at 8 months of age indicated a main effect of Block $(F(1$, $109.001)=24.523, p<.001, d=0.96)$. Infants had a higher proportion of correct anticipations in the preswitch block $(M=0.704, S E=.025)$ than in the postswitch block $(M=0.504, S E=.030)$. However, the main effect of Group $(F(1,108.001)=0.102$, $p=.751)$ was nonsignificant.

In the LMM at 24 months of age, significant main effects of Block $(F(1,119)=48.837, p<.001, d=1.39)$ and $\operatorname{Group}(F(1,119)=5.269, p=.023, d=0.43)$ were observed. Toddlers had a higher proportion of correct anticipations in the preswitch block $(M=0.769$, $S E=.030)$ than in the postswitch block $(M=0.449$, $S E=.030)$. In addition, the nonwaking group $(M=0.655, S E=.029)$ had a higher proportion of correct anticipations than the waking group $(M=0.563$, $S E=.027)$. Together, these analyses indicated that the differences between the groups were more pronounced at 24 months of age. The Group $\times$ Block interaction remained nonsignificant in both age-specific analyses $(8$ months, $F(1,119.589)=0.038, p=.845$; 24 months $F(1,119)=0.096, p=.757)$; thus, the differences between groups were not specific only to the preswitch or postswitch block. Statistics of the final LMM models are included in Table 3.

The behavioral EF tasks showed no significant differences between the two groups. In the Spin the Pot task, the performance of the waking $(M=7.53$, $S D=2.612)$ and nonwaking group $(M=7.33$, $S D=2.678)$ did not differ $(t(116)=0.405, p=.686)$. In addition, in the Snack Delay task no differences between the waking $(M=36.7 \mathrm{~s}, S D=24.0 \mathrm{~s})$ and the nonwaking group $(M=39.3 \mathrm{~s}, S D=23.3 \mathrm{~s})$ were found $(t(116)=-0.577, p=.565)$.

There were no clearly significant differences between the waking group and the nonwaking group in any of the different BRIEF-P indexes ( $t$-scores), with only the FI suggesting a marginal difference between the waking and the nonwaking group $(t(83)=1.668, p=.099 ; \quad$ waking group $M=64.33, \quad S D=11.97 ; \quad$ nonwaking group $M=60.38, S D=9.17)$. Parental ratings in the ISCI index $(t(83)=0.05, p=.961$; waking $M=50.13$, $S D=9.10$; nonwaking group $M=50.03, S D=8.92$ ) 


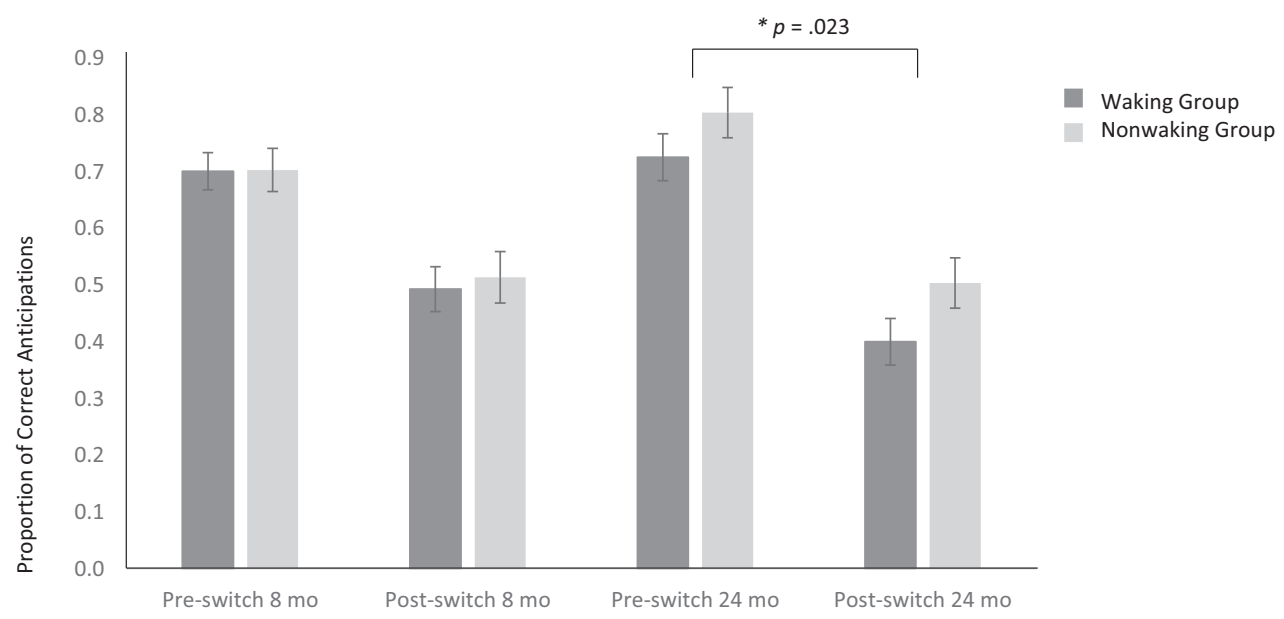

Figure 2. Group differences in the average performance of the Switch task at 8 and 24 months of age. Note. Error bars depict the standard error of the mean.

Table 3

Statistics of the Final Models for the Switch Task Data

\begin{tabular}{|c|c|c|c|c|c|}
\hline & Estimate & $S E$ & $95 \% \mathrm{CI}$ & $t$ & $p$ \\
\hline \multicolumn{6}{|c|}{ Across both ages } \\
\hline Intercept & .503 & .025 & {$[.454, .552]$} & 20.128 & $<.001$ \\
\hline Group $^{a}$ & -.054 & .025 & {$[-.103,-.003]$} & -2.119 & .035 \\
\hline Block $^{\mathrm{b}}$ & .262 & .033 & {$[.197, .327]$} & 7.957 & $<.001$ \\
\hline \multicolumn{6}{|l|}{8 months } \\
\hline Intercept & .486 & .031 & {$[.425, .547]$} & 15.708 & $<.001$ \\
\hline Group $^{a}$ & -.001 & .031 & {$[-.051, .072]$} & -0.319 & .751 \\
\hline Block $^{\mathrm{b}}$ & .199 & .040 & {$[.120, .280]$} & 4.942 & $<.001$ \\
\hline \multicolumn{6}{|l|}{24 months } \\
\hline Intercept & .495 & .037 & {$[.422, .568]$} & 13.354 & $<.001$ \\
\hline Group $^{\mathrm{a}}$ & -.091 & .039 & {$[-.170,-.013]$} & -2.295 & .023 \\
\hline Block $^{\mathrm{b}}$ & .319 & .046 & {$[.229, .410]$} & 6.988 & $<.001$ \\
\hline
\end{tabular}

${ }^{a}$ Waking group versus nonwaking group. ${ }^{\mathrm{b}}$ Preswitch block versus postswitch block.

and EMI index showed no differences between the two groups $(t(83)=1.343, p=.183$; waking group $M=55.23, \quad S D=12.98 ; \quad$ nonwaking group $M=51.73, S D=10.35$ ). In addition, no differences in the overall GEC index between the waking group $(M=51.83, S D=11.02)$ and nonwaking group $(M=49.68, S D=9.18) \quad$ were observed $(t(83)=0.961, p=.339)$.

In the 8-month actigraphy data, the mean activity score during active nocturnal periods differed between the groups, $t(126)=2.883, p=.005$, $d=0.52$. The mean activity scores during active periods were greater in the waking group $(M=126.97, S D=48.75)$ than in the nonwaking group $(M=102.06, S D=46.59)$, demonstrating that the infants in the waking group showed more nocturnal activity during activity periods than the infants in the nonwaking group. Actigraphy-based night awakening data analyzed with the smoothing algorithm further validated our group formation based on parent reports, $t(121)=3.179, p=.002$, $d=0.58$, with the waking group having more night awakenings $(M=6.2, S D=2.1)$ than the nonwaking group $(M=4.9, S D=2.2)$. Night awakenings based on the smoothing algorithm correlated positively with parent-reported signaled night awakenings, $r=.245, p=.011$. However, the mean activity score correlated only marginally with the number of parent-reported night awakenings, $r=.158$, $p=.094$, respectively.

\section{Discussion}

The aim of this study was to longitudinally investigate $\mathrm{EF}$ in infants with and without signaled night awakenings at 8 and 24 months of age with a comprehensive set of methods. For this study, we used an eye movement-based method (i.e., the Switch task) for investigating EF at both ages. Our aim was to find out whether signaled night awakening is associated with EF development, and whether the influence of signaled night awakening on infant EF would be evident already at 8 months of age. An exploratory approach was adopted and no definite hypothesis was formed for the 8-month-old infants, since different sleep parameters and EF have not been previously studied in infants under 1 year of age. At 24 months of age, however, in concordance with previous studies with older children (Sadeh et al., 2002; Sadeh et al., 2015), we 
expected that toddlers with several signaled night awakenings would show poorer performance in EF tasks and parent-rated EF than toddlers without signaled night awakening due to the early-onset fragmented sleep. Our results shed new light on the connections between night awakening and EF already during the first 2 years of life, as measured with versatile and novel methods.

Consistent with our hypothesis, the Switch task results showed that the waking group performed worse on this EF task than the nonwaking group. They had fewer anticipatory looks toward the correct stimulus location and were less able to inhibit their previous response and learn a new conflicting response compared to the nonwaking group. Our finding is consistent with that of Sadeh et al. (2002, 2015), who showed that fragmented sleep is connected to diminished EF in preschool- and schoolaged children when measured with a computerized method. The expected interactions were nonsignificant and, therefore, it cannot be concluded whether the differences are more pronounced at 8 or 24 months of age, or in the first or second block of the Switch task. Considering that our central research question was whether the possible differences in EF between groups are observable already at 8 months, we nevertheless decided to conduct the analyses separately for 8 and 24 months of age, although we acknowledge that probing subgroup differences may not be advisable when the higherorder interaction is nonsignificant (Nieuwenhuis, Forstmann, \& Wagenmakers, 2011). According to these age-specific analyses, the differences between the waking and the nonwaking group were not yet evident at 8 months of age. At 24 months of age, however, the waking group performed worse than the nonwaking group, thus suggesting that the differences between groups were more evident at 24 months of age. It should be stressed that these conclusions are only tentative, since the Group $\times$ Age interaction was nonsignificant. The overall analysis as well as the age-specific analysis at 24 months of age showed that the waking group performed worse on both the learning and inhibition part of the task. One possible explanation for this finding could be that EF is still maturing in infancy and toddlerhood, and the different domains of EF are not yet distinguishable (Espy et al., 2011; Shing et al., 2010; Wiebe et al., 2008). Another possibility is insufficient statistical power to detect effects of age and block especially in the three-way interaction analysis.

Contrary to our expectations, there were no differences in $\mathrm{EF}$ between the waking and nonwaking group when traditional behavioral measures of EF were used. However, our findings are consistent with those of Bernier et al. (2010), who also used behavioral methods and did not find a connection between night awakenings and later EF. Regarding the discrepancies between our behavioral and the Switch task results, it could be the case that computerized methods recording looking behavior on a millisecond scale are more sensitive than behavioral methods for assessing infant and toddler EF, thus being better able to detect differences in the normal range of performance. Another possibility is that the tasks used tapped into different aspects of EF. The subdomains of EF are highly interrelated and it may not be possible to design tasks that only tap into one aspect of EF (Diamond, 2013). In addition, EF undergoes rapid development in infancy, potentially making it even more difficult to distinguish its different aspects (Espy et al., 2011; Shing et al., 2010; Wiebe et al., 2008).

Also contrary to our expectations, the parental ratings of EF between the waking and nonwaking group did not differ clearly. Only a marginal difference was found in the parental ratings of flexibility, suggesting that toddlers in the waking group could be less able to perform working memory and set shifting tasks than toddlers in the nonwaking group. These findings were surprising, since in previous studies, the BRIEF-P has been found to relate to the laboratory assessments of EF and to distinguish performance in typically developing preschoolers (Ferrier, Bassett, \& Denham, 2014; Garon, Piccinin, \& Smith, 2016). It is possible, however, that from a parent's point of view it is difficult to distinguish the small differences in currently emerging EF skills in toddlers as young as 24 months of age. In addition, the response rate of the BRIEF-P questionnaire was lower than in the other measures used in the study (waking group $n=49$ and nonwaking group $n=38$ ), and this could have resulted in the differences between pairwise comparisons not being statistically significant. The lower response rate was possibly caused by the protocol, which resulted in some families forgetting to return the questionnaire at the second research visit.

In this study, we were primarily interested in parent-reported signaled night awakening. However, in addition to parent reports, actigraphy data were available for a majority of children at 8 months of age. In the 8-month data, the actigraphy measurements provided support for the group formation based on parent reports, as infants in the waking group had more actigraphy-based night 
awakenings than the nonwaking group. There was a substantial drop in the available actigraphy measurements at 24 months of age and due to the loss of power, the actigraphy data at 24 months of age were not analyzed. Thus, while bearing in mind that parent-reported signaled night awakening and more objective measures of sleep, such as actigraphy, do not represent identical measures of night awakening (Acebo et al., 2005; Sadeh, 2004), the current results support the use of parent reports of infant night awakening. It should also be noted that the actigraphy-based sleep measures are based on limited number of nights, whereas parent reports describe sleep across longer periods. In this study, we used a smoothing algorithm for the actigraphybased activity data to derive a number of night awakenings more consistent with signaled night awakenings (Sitnick et al., 2008). Using this algorithm, the actigraphy derived night awakenings and parent-reported signaled night awakenings correlated positively. However, the number of night awakenings indicated by the smoothing algorithm was greater than what the parent had reported (waking group 6.2 vs. 3.8, nonwaking group 4.9 vs. $0.9)$. The smoothing algorithm was originally developed for preschool-aged children, whereas we used it with 8-month-old infants, which could partly explain the discrepancy in the number of night awakenings between the parent-reported and actigraphy-based data.

According to our results, signaled night awakening may affect EF in infancy and toddlerhood, as shown by the Switch task results, even in a sample where signaled night awakenings diminished in both groups prior to the age of 24 months (Mäkelä et al., 2018). The two groups of toddlers still differed in the number of night awakenings at the age of 24 months, even though the differences had become smaller. Consistent with this line of reasoning, Touchette et al. (2005) showed that shorter sleep before the age of 41 months is a risk factor for cognitive functioning despite the sleep characteristics in that group normalizing later on. Thus, it seems that sleep characteristics in infancy could affect development, even when particular sleep characteristics tend to normalize later on.

Our results support the notion that the development of EF follows somewhat distinctive pathways in infants with and without fragmented sleep. It should be noted, however, that although there were differences between the two groups, the effect sizes were rather small. In addition, two out of three measures did not support the notion that signaled night awakening is connected to EF even though our sample size was fairly large. This finding could be due to the sensitivity of the different measures to detect individual differences in EF or, alternatively, the discrepancies between the results may reflect a true lack of association between signaled night awakening and components of EF. Another possible limitation of our study is that our sample consisted of white infants of mainly middle-class origin, limiting the generalizability of the results to other ethnicities and socio-demographic groups. Finally, the interpretation of the results particularly regarding the 24-month behavioral assessments is limited by the absence of data from the Trucks task, which we were not able to analyze due to inconsistencies in the task presentation.

According to our age-specific results, it seems that the differences between the two groups were more pronounced at 24 months than at 8 months of age. It could be the case that EF skills are still poorly developed at the age of 8 months, making it difficult to distinguish between the groups accurately (Espy et al., 2011; Shing et al., 2010; Wiebe et al., 2008). Another possibility is that the effect of signaled night awakening is evident longitudinally and, therefore, more clearly observed at 24 months of age, as suggested by prior research (Bernier et al., 2010; Bernier et al., 2013; Dearing, McCartney, Marshall, \& Warner, 2001; Dionne et al., 2011; Gertner et al., 2002; Sadeh et al., 2015). The group differences in EF were not affected by differences in overall development, since our previous study with the same sample showed that there were no differences in overall psychomotor development between the waking and nonwaking group at 8 and 24 months of age (Mäkelä et al., 2018). It should be noted that the groups did differ in several sleep characteristics other than just night awakenings as shown in our previous study (Mäkelä et al., 2018). The waking group also had a shorter total sleep duration and they spent more time awake during the night. These other sleep characteristics were covaried in the analyses, and they did not affect our findings. Nevertheless, in future studies, shorter sleep duration should be taken into account, since studies with school-aged children have shown that shorter sleep duration is connected to lower performance in EF tasks (Astill et al., 2012; Steenari et al., 2003; Taveras et al., 2017).

An important factor in the phenomenon of night awakening is the ability to fall asleep alone, for which self-regulation skills are essential. Moreover, EF and emotion regulation are both considered under the concept of self-regulation, and previous studies have shown that they are interconnected (Carlson \& Wang, 2007). The connection between 
EF and emotion regulation highlights the importance of a broader view of self-regulation skills both in infant night awakening and performance in EFrelated tasks. It would be interesting to study further how signaled night awakening in infancy is connected to different aspects of self-regulation besides EF.

In conclusion, our results support the notion that fragmented sleep is connected to EF when measured with sensitive methods that are able to discriminate performance in the normal range, and that the differences can be observable already in children under 2 years of age. Children with several signaled night awakenings were less able to learn new stimulus sequences and inhibit their previously learned responses compared to children without signaled night awakenings, as measured with an eye movement-based computer task. In the parental ratings of $\mathrm{EF}$, the groups differed only marginally, and the two groups of toddlers did not differ in behavioral measures of EF, perhaps due to the behavioral measures being less sensitive than computerized measures to early differences in EF. According to our previous work (Mäkelä et al., 2018), the two groups did not differ in overall psychomotor development at 8 and 24 months of age, showing that the differences in EF are not a reflection of differences in overall psychomotor development. According to our results, it seems that in children with early-onset fragmented sleep, the development of EF follows somewhat distinctive pathways when compared to children without fragmented sleep already during the first 2 years of life. However, the effect sizes were rather small and, thus, the results of the study should be replicated in an independent sample. Computerized tasks and eye-tracking paradigms are promising methods that will advance knowledge on the associations of different sleep characteristics and infant development. In the future, fragmented sleep and its associations with different aspects of self-regulation should be further investigated.

\section{References}

Acebo, C., Sadeh, A., Seifer, R., Tzischinsky, O., Hafer, A., \& Carskadon, M. A. (2005). Sleep/wake patterns derived from activity monitoring and maternal report for healthy 1- to 5-year-old children. Sleep, 28, 15681577. https: / / doi.org/10.1093/sleep/28.12.1568

Adair, R., Zuckerman, B., Bauchner, H., Philipp, B., \& Levenson, S. (1992). Reducing night waking in infancy: A primary care intervention. Pediatrics, 89, 585-588.

Anders, T. F. (1978). Home-recorded sleep in 2- and 9month-old infants. Journal of the American Academy of
Child Psychiatry, 17, 421-432. https://doi.org/10.1016/ S0002-7138(09)62298-6

Astill, R. G., Van der Heijden, K. B., Van IJzendoorn, M. H., \& Van Someren, E. J. W. (2012). Sleep, cognition, and behavioral problems in school-age children: A century of research meta-analyzed. Psychological Bulletin, 138, 1109-1138. https:/ / doi.org/10.1037/a0028204

Bernier, A., Beauchamp, M. H., Bouvette-Turcot, A., Carlson, S. M., \& Carrier, J. (2013). Sleep and cognition in preschool years: Specific links to executive functioning. Child Development, 84, 1542-1553. http://dx.doi.org/10. 1111/cdev.12063

Bernier, A., Carlson, S. M., Bordeleau, S., \& Carrier, J. (2010). Relations between physiological and cognitive regulatory systems: Infant sleep regulation and subsequent executive functioning. Child Development, 81, 17391752. https: / / doi.org/10.1111/j.1467-8624.2010.01507.x

Best, J. R., \& Miller, P. H. (2010). A developmental perspective on executive function. Child Development, 81, 16411660. https: / / doi.org/10.1111/j.1467-8624.2010.01499.x

Boergers, J., Hart, C., Owens, J. A., Streisand, R., \& Spirito, A. (2007). Child sleep disorders: Associations with parental sleep duration and daytime sleepiness. Journal of Family Psychology, 21, 88-94. https://doi.org/10. 1037/0893-3200.21.1.88

Borella, E., Carretti, B., \& Pelegrina, S. (2010). The specific role of inhibition in reading comprehension in good and poor comprehenders. Journal of Learning Disabilities, 43, 541-552. https: / / doi.org/10.1177/0022219410371676

Bridgett, D. J., Burt, N. M., Edwards, E. S., \& DeaterDeckard, K. (2015). Intergenerational transmission of self-regulation: A multidisciplinary review and integrative conceptual framework. Psychological Bulletin, 141, 602-654. https:/ / doi.org/10.1037/a0038662

Brown, T. E., \& Landgraf, J. M. (2010). Improvements in executive function correlate with enhanced performance and functioning and health-related quality of life: Evidence from 2 large, double-blind, randomized, placebocontrolled trials in ADHD. Postgraduate Medicine, 122, 42-51. https://doi.org/10.3810/pgm.2010.09.2200

Carlson, S. M. (2005). Developmentally sensitive measures of executive function in preschool children. Developmental Neuropsychology, 28, 595-616. https://doi.org/10. $1207 /$ s15326942dn2802_3

Carlson, S. M., \& Wang, T. S. (2007). Inhibitory control and emotion regulation in preschool children. Cognitive Development, 22, 489-510. https://doi.org/10.1016/j.c ogdev.2007.08.002

Dahl, R. E. (1996a). The impact of inadequate sleep on children's daytime cognitive function. Seminars in Pediatric Neurology, 3, 44-50. https://doi.org/10.1016/ S1071-9091(96)80028-3

Dahl, R. E. (1996b). The regulation of sleep and arousal: Development and psychopathology. Development and Psychopathology, 8, 3-27. https://doi.org/10.1017/ S0954579400006945

Davis, J. C., Marra, C. A., Najafzadeh, M., \& LiuAmbrose, T. (2010). The independent contribution of 
executive functions to health related quality of life in older women. BMC Geriatrics, 10, 16-16. https://doi. org/10.1186/1471-2318-10-16

Dearing, E., McCartney, K., Marshall, N. L., \& Warner, R. M. (2001). Parental reports of children's sleep and wakefulness: Longitudinal associations with cognitive and language outcomes. Infant Behavior $\mathcal{E}$ Development, 24, 151-170. https://doi.org/10.1016/S0163-6383(01) 00074-1

Diamond, A. (2013). Executive functions. Annual Review of Psychology, 64, 135-168. https://doi.org/10.1146/an nurev-psych-113011-143750

Dionne, G., Touchette, E., Forget-Dubois, N., Petit, D., Tremblay, R. E., Montplaisir, J. Y., \& Boivin, M. (2011). Associations between sleep-wake consolidation and language development in early childhood: A longitudinal twin study. Sleep: Journal of Sleep and Sleep Disorders Research, 34, 987-995. https://doi.org/10.5665/SLEEP. 1148

Duncan, G. J., Dowsett, C. J., Claessens, A., Magnuson, K., Huston, A. C., Klebanov, P., . . . American Psychological Association. (2007). School readiness and later achievement. Developmental Psychology, 43, 1428-1446. https: / / doi.org/10.1037/0012-1649.43.6.1428

Espy, K. A., Sheffield, T. D., Wiebe, S. A., Clark, C. A. C., \& Moehr, M. J. (2011). Executive control and dimensions of problem behaviors in preschool children. Journal of Child Psychology and Psychiatry, 52, 33-46. https:/ / doi.org/10.1111/j.1469-7610.2010.02265.x

Ferrier, D. E., Bassett, H. H., \& Denham, S. A. (2014). Relations between executive function and emotionality in preschoolers: Exploring a transitive cognition-emotion linkage. Frontiers in Psychology, 5, 487. https://doi. org/10.3389/fpsyg.2014.00487

Forssman, L., Ashorn, P., Ashorn, U., Maleta, K., Matchado, A., Kortekangas, E., \& Leppänen, J. M. (2017). Eyetracking-based assessment of cognitive function in lowresource settings. Archives of Disease in Childhood, 102, 301-302. https://doi.org/10.1136/archdischild-2016310525

Garon, N., Bryson, S. E., \& Smith, I. M. (2008). Executive function in preschoolers: A review using an integrative framework. Psychological Bulletin, 134, 31-60. https:// doi.org/10.1037/0033-2909.134.1.31

Garon, N. M., Piccinin, C., \& Smith, I. M. (2016). Does the BRIEF-P predict specific executive function components in preschoolers? Applied Neuropsychology: Child, 5, 110118. https:/ /doi.org/10.1080/21622965.2014.1002923

Gay, C. L., Lee, K. A., \& Lee, S. (2004). Sleep patterns and fatigue in new mothers and fathers. Biological Research for Nursing, 5, 311-318. https://doi.org/10. $1177 / 1099800403262142$

Gertner, S., Greenbaum, C. W., Sadeh, A., Dolfin, Z., Sirota, L., \& Ben-Nun, Y. (2002). Sleep-wake patterns in preterm infants and 6 month's home environment: Implications for early cognitive development. Early Human Development, 68, 93-102. https://doi.org/10. 1016/S0378-3782(02)00018-X
Gioia, G. A., Espy, K. A., \& Isquith, P. K. (2003). Behavior Rating Inventory of Executive Function-Preschool version. Odessa, FL: Psychological Assessment Resources.

Hughes, C., \& Ensor, R. (2005). Executive function and theory of mind in 2 year olds: A family affair? Developmental Neuropsychology, 28, 645-668. https://doi.org/ $10.1207 /$ s15326942dn2802_5

Hysing, M., Harvey, A. G., Torgersen, L., Ystrom, E., Reichborn-Kjennerud, T., \& Sivertsen, B. (2014). Trajectories and predictors of nocturnal awakenings and sleep duration in infants. Journal of Developmental and Behavioral Pediatrics, 35, 309-316. https://doi.org/10. 1097 / DBP.0000000000000064

Hysing, M., Sivertsen, B., Garthus-Niegel, S., \& EberhardGran, M. (2016). Pediatric sleep problems and socialemotional problems. A population-based study. Infant Behavior E Development, 42, 111-118. https://doi.org/ 10.1016/j.infbeh.2015.12.005

Isquith, P. K., Crawford, J. S., Espy, K. A., \& Gioia, G. A. (2005). Assessment of executive function in preschoolaged children. Mental Retardation and Developmental Disabilities Research Reviews, 11, 209-215. https://doi.org/ 10.1002/mrdd.20075

Karraker, K. (2008). The role of intrinsic and extrinsic factors in infant night waking. Journal of Early and Intensive Behavior Intervention, 5, 108-121. https://doi.org/10. $1037 /$ h0100426

Kochanska, G., Murray, K. T., \& Harlan, E. T. (2000). Effortful control in early childhood: Continuity and change, antecedents, and implications for social development. Developmental Psychology, 36, 220-232. https: / / doi.org/10.1037/0012-1649.36.2.220

Kovács, Á. M., \& Mehler, J. (2009). Cognitive gains in 7month-old bilingual infants. Proceedings of the National Academy of Sciences of the United States of America, 106, 6556-6560. https://doi.org/10.1073/pnas.0811323106

Kushida, C. A., Chang, A., Gadkary, C., Guilleminault, C., Carrillo, O., \& Dement, W. C. (2001). Comparison of actigraphic, polysomnographic, and subjective assessment of sleep parameters in sleep-disordered patients. Sleep Medicine, 2, 389-396. https://doi.org/10. 1016/S1389-9457(00)00098-8

Lam, J. C., Mahone, E. M., Mason, T., \& Scharf, S. M. (2011). The effects of napping on cognitive function in preschoolers. Journal of Developmental and Behavioral Pediatrics, 32, 90-97. https://doi.org/10.1097/DBP.0b 013e318207ecc7

Lehto, J. E., Juujärvi, P., Kooistra, L., \& Pulkkinen, L. (2003). Dimensions of executive functioning: Evidence from children. British Journal of Developmental Psychology, 21, 59-80. https:/ / doi.org/10.1348/026151003321164627

Leppänen, J., Forssman, L., Kaatiala, J., Yrttiaho, S., \& Wass, S. (2015). Widely applicable MATLAB routines for automated analysis of saccadic reaction times. Behavior Research Methods, 47, 538-548. https://doi.org/ 10.3758/s13428-014-0473-z

Mäkelä, T. E., Peltola, M. J., Nieminen, P., Juulia Paavonen, E., Saarenpää-Heikkilä, O., Paunio, T., \& 
Kylliäinen, A. (2018). Night awakening in infancy: Developmental stability and longitudinal associations with psychomotor development. Developmental Psychology, 54, 1208-1218. https://doi.org/10.1037/ dev0000503

Meltzer, L. J., \& Mindell, J. A. (2007). Relationship between child sleep disturbances and maternal sleep, mood, and parenting stress: A pilot study. Journal of Family Psychology, 21, 67-73. https://doi.org/10.1037/ 0893-3200.21.1.67

Mindell, J., Kuhn, B., Lewin, D., Meltzer, L., \& Sadeh, A. (2006). Behavioral treatment of bedtime problems and night wakings in infants and young children-An American Academy of Sleep Medicine review. Sleep, 29, 1263-1276. https://doi.org/10.1093/sleep/29.10.1263

Miyake, A., Friedman, N. P., Emerson, M. J., Witzki, A. H., Howerter, A., \& Wager, T. D. (2000). The unity and diversity of executive functions and their contributions to complex "frontal lobe" tasks: A latent variable analysis. Cognitive Psychology, 41, 49-100. https:/ / doi.org/10. 1006/cogp.1999.0734

Nieuwenhuis, S., Forstmann, B. U., \& Wagenmakers, E. (2011). Erroneous analyses of interactions in neuroscience: A problem of significance. Nature Neuroscience, 14, 1105-1107. https://doi.org/10.1038/nn.2886

Nigg, J. T. (2017). Annual research review: On the relations among self-regulation, self-control, executive functioning, effortful control, cognitive control, impulsivity, risk-taking, and inhibition for developmental psychopathology. Journal of Child Psychology and Psychiatry, 58, 361-383. https://doi.org/10.1111/jcpp.12675

Oakley, N. R. (1997). Validation with polysomnography of the sleepwatch sleep/wake scoring algorithm used by the actiwatch activity monitoring system. Technical report. Bend, OR: Mini-Mitter.

Paavonen, E. J., Saarenpää-Heikkilä, O., Pölkki, P., Kylliäinen, A., Porkka-Heiskanen, T., \& Paunio, T. (2017). Maternal and paternal sleep during pregnancy in the child-sleep birth cohort. Sleep Medicine, 29, 47-56. https:/ / doi.org/10.1016/j.sleep.2016.09.011

Petit, D., Touchette, E., Tremblay, R. E., Boivin, M., \& Montplaisir, J. (2007). Dyssomnias and parasomnias in early childhood. Pediatrics, 119, e1016-e1025. https:// doi.org/10.1542/peds.2006-2132

Sadeh, A. (2004). A brief screening questionnaire for infant sleep problems: Validation and findings for an internet sample. Pediatrics, 113, e570-e577. https://doi. org/10.1542/peds.113.6.e570

Sadeh, A., De Marcas, G., Guri, Y., Berger, A., Tikotzky, L., \& Bar-Haim, Y. (2015). Infant sleep predicts attention regulation and behavior problems at 3-4 years of age. Developmental Neuropsychology, 40, 122-137. https:/ / doi.org/10.1080/87565641.2014.973498

Sadeh, A., Flint-Ofir, E., Tirosh, T., \& Tikotzky, L. (2007). Infant sleep and parental sleep-related cognitions. Journal of Family Psychology, 21, 74-87. https://doi.org/10. 1037/0893-3200.21.1.74
Sadeh, A., Gruber, R., \& Raviv, A. (2002). Sleep, neurobehavioral functioning, and behavior problems in schoolage children. Child Development, 73, 405-417. https:// doi.org/10.1111/1467-8624.00414

Sadeh, A., Gruber, R., \& Raviv, A. (2003). The effects of sleep restriction and extension on school-age children: What a difference an hour makes. Child Development, 74, 444-455. https://doi.org/10.1111/1467-8624. 7402008

Sadeh, A., Mindell, J. A., Luedtke, K., \& Wiegand, B. (2009). Sleep and sleep ecology in the first 3 years: A web-based study. Journal of Sleep Research, 18, 60-73. https:/ / doi.org/10.1111/j.1365-2869.2008.00699.x

Shing, Y. L., Lindenberger, U., Diamond, A., Li, S., \& Davidson, M. C. (2010). Memory maintenance and inhibitory control differentiate from early childhood to adolescence. Developmental Neuropsychology, 35, 679-697. https: / / doi.org/10.1080/87565641.2010.508546

Sitnick, S. L., Goodlin-Jones, B. L., \& Anders, T. F. (2008). The use of actigraphy to study sleep disorders in preschoolers: Some concerns about detection of nighttime awakenings. Sleep, 31, 395-401. https://doi.org/ 10.1093/sleep/31.3.395

Steenari, M., Vuontela, V., Paavonen, E., Carlson, S., Fjallberg, M., \& Aronen, E. (2003). Working memory and sleep in 6-to 13-year-old schoolchildren. Journal of the American Academy of Child and Adolescent Psychiatry, 42, 85-92. https://doi.org/10.1097/01.CHI.0000024911. 60748.D3

Taveras, E. M., Rifas-Shiman, S. L., Bub, K. L., Gillman, M. W., \& Oken, E. (2017). Prospective study of insufficient sleep and neurobehavioral functioning among school-age children. Academic Pediatrics, 17, 625-632. https://doi.org/10.1016/j.acap.2017.02.001

Touchette, E., Petit, D., Paquet, J., Boivin, M., Japel, C., Tremblay, R. E., \& Montplaisir, J. Y. (2005). Factors associated with fragmented sleep at night across early childhood. Archives of Pediatrics E Adolescent Medicine, 159, 242. https://doi.org/10.1001/archpedi.159.3.242

Wass, S., Porayska-Pomsta, K., \& Johnson, M. (2011). Training attentional control in infancy. Current Biology, 21, 1543-1547. https://doi.org/10.1016/j.cub.2011.08. 004

Wiebe, S. A., Espy, K. A., \& Charak, D. (2008). Using confirmatory factor analysis to understand executive control in preschool children: I. latent structure. Developmental Psychology, 44, 575-587. https://doi.org/ 10.1037/0012-1649.44.2.575

Wolfe, C. D., Zhang, J., Kim-Spoon, J., \& Bell, M. A. (2014). A longitudinal perspective on the association between cognition and temperamental shyness. International Journal of Behavioral Development, 38, 266-276. https: / / doi.org/10.1177/0165025413516257

Zelazo, P. D., Carter, A., Reznick, J. S., \& Frye, D. (1997). Early development of executive function: A problemsolving framework. Review of General Psychology, 1, 198-226. https:/ / doi.org/10.1037/1089-2680.1.2.198 